\title{
Diabetes and Ramadan
}

Sir,

The holy month of Ramadan is the 9th month of the Muslim calendar wherein Muslims all over the world observe daylight fasting as one of the five pillars of the Islamic faith. As per a recent estimate, there are 1.82 billion Muslims worldwide, comprising $18-25 \%$ of the world population. Fasting during the month of Ramadan is an obligatory duty for all healthy, adult Muslims, although there are exemptions for people with serious medical conditions, like those with diabetes mellitus. Fasting is not meant to create an undue hardship on the Muslim individual. The Quran particularly exempts the sick from the duty of fasting (Holy Quran, Al-Bakarah, 183 185), especially if there is a potential harm to the individual because of fasting. Nevertheless, many patients with diabetes mellitus insist on fasting during Ramadan, thereby creating a medical challenge for themselves and their physicians.

The first comprehensive recommendations for the management of diabetes during Ramadan were published by Al-Arouj et al in 2005, an updated version of the recommendations was published by the same authors in 2010. ${ }^{2}$ In 2016, the International Diabetes Federation (IDF), and Diabetes and Ramadan (DAR) International Alliance came together to deliver comprehensive guidelines on this important topic ${ }^{3}$. The IDF-DAR Practical Guidelines offer healthcare professionals (HCPs) with appropriate background knowledge and useful recommendations for helping patients with diabetes to participate in Ramadan fasting while minimising the risk of diabetes complications. These guidelines include several key areas, like epidemiology, physiological aspects of fasting, risk stratification, nutrition advice, medication adjustment, and

\begin{tabular}{|l|l|}
\multicolumn{2}{c}{ Access this article online } \\
\hline
\end{tabular}

the implementation of recommendations. The regular theme throughout the guidelines is the importance of individualisation and education within a diabetes management plan.

The IDF-DAR Practical Guidelines will significantly augment information on diabetes and Ramadan fasting, thereby empowering HCPs to provide the most up-to-date advice and the best possible support to their patients. Previous guidelines which were based on Epidemiology of Diabetes and Ramadan (EPIDIAR) study, categorised the diabetes patients into 4 groups. But the present IDF-DAR Practical Guidelines divided the diabetes patients into 3 categories:

Category 1 (Very high risk) - When one or more of the following are present:

Severe hypoglycaemia/ DKA/ hyperosmolar hyperglycaemic coma within the 3 months prior to Ramadan; history of recurrent hypoglycaemia or hypoglycaemia unawareness; poorly controlled type 1 diabetes; acute illness; pregnancy in a case of pre-existing diabetes (or gestational diabetes treated with insulin or sulfonylureas); CKD stage 4 \& 5 (or Chronic dialysis); advanced macrovascular diabetes complications; and old age with ill health. The patient in this group must not fast.

Category 2 (High risk) - When one or more of the following are present: type 2 diabetes with sustained poor glycemia;

\section{Correspondence: \\ Dr. Moomin Hussain Bhat, DM \\ Department of Endocrinology, SKIMS \\ Email:moomin_48@rediffmail.com}

How to cite this article: Bhat MH, Peerzada OA, Masoodi SR. Diabetes and Ramadan. jms [Internet]. 2019May28 [cited $2019 \mathrm{M}$ a y 28 ]; $22(2)$. Ava i 1 a b 1 e from : http://www.jmsskims.org/index.php/jms/article/view/462

Received: 28-05-2019 Accepted: 28-05-2019 
Bhat MH; et al; Diabetes and Ramadan

well-controlled type 1 diabetes; well-controlled type 2 diabetes patients on MDI or mixed insulin; pregnant patients with type 2 diabetes or gestational diabetes, controlled by diet only or metformin; CKD stage 3 ; stable macrovascular diabetes complications; patients having with comorbid conditions that pose additional risk factors; people with diabetes performing intense physical labour; treatment with drugs that may affect cognitive function. The patients in this group should not fast.

The guidelines recommend that if patients with category 1 and 2 insist on keeping the fasting, they should be provided with structured education; Be followed by a qualified diabetes team; Check their blood glucose regularly (SMBG); Adjust medication dose as per recommendations; Be prepared to break the fast in case of hypo- or hyperglycaemia; Be prepared to stop the fast in case of frequent hypo- or hyperglycaemia or worsening of other related medical conditions.

Category 3 (Moderate/ low-risk) - Condition which includes well-controlled type 2 diabetes managed with lifestyle therapy, metformin, acarbose, thiazolidinediones, 2nd-generation sulfonylureas; Incretin-based therapy; SGLT2 inhibitors; Basal insulin. The decision to use a license not to fast is based on discretion to medical opinion and adeptness of the individual to tolerate fast. Patients who fast should be provided with structured education, Check their blood glucose regularly (SMBG), Adjust medication dose as per recommendations.

\section{REFERENCES:}

1. Al-Arouj M, Bougeurra R, Buse J, Hafez S, Hassanein M, Ibrahim MA, Ismail-Beigi F, El-Kebbi I, Khatib O, Kishawi S, Al-Madani A, Mishal AA, Al-Maskari M, Nakhi AB, Al-Rubean K: Recommendations for management of diabetes during Ramadan. Diabetes Care 2005;28: 23052311

2. Al-Arouj M, Assaad-Khalil S, Buse J, Fahdil I, Fahmy M, Hafez S, Hassanein M, Ibrahim MA, Kendall D, Kishawi S, Al-Madani A, Nakhi AB, Tayeb K, Thomas A. Recommendations for management of diabetes during Ramadan: update 2010. Diabetes Care. 2010;33(8):1895-902.

3. "Why Muslims are the world's fastest-growing religious group". Pew Research Centre. April 2017. Retrieved 24 April 2017.

Dr. Moomin Hussain Bhat, MD, DM

Dr. Peerzada Ovais Ahmad, MBBS

Dr. Shariq Rashid Masoodi, MD, DM

Department of Endocrinology,

SKIMS, Srinagar (J\&K), India 190011 